
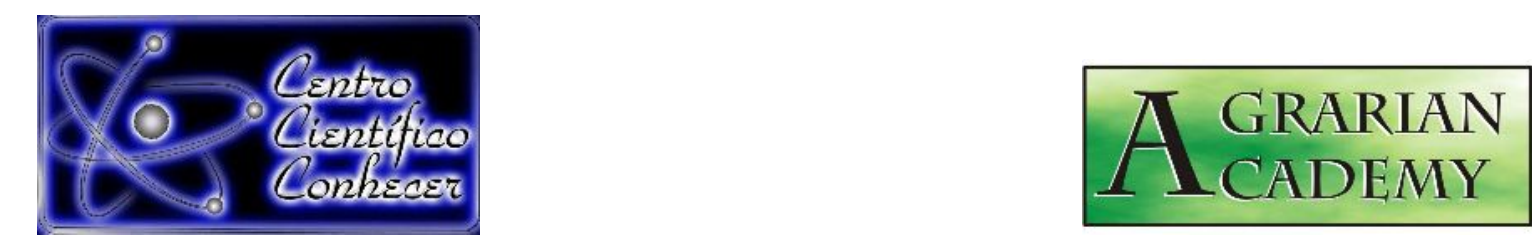

\title{
COMPOSIÇÃO ARBÓREA DA FLORESTA ESTACIONAL DECIDUAL EM RELAÇÃO A HETEROGENEIDADE AMBIENTAL NO REBORDO DO PLANALTO MERIDIONAL, RS
}

\author{
Francieli de Fátima Missio ${ }^{1}$, Solon Jonas Longhi ${ }^{2}$ \\ 1Doutora e Pós - doutoranda em Engenharia Florestal - UFSM. \\ franmissio@yahoo.com.br, Santa Maria, Brasil. \\ 2Professor Doutor do Programa de Pós-graduação em Engenharia Florestal - UFSM, \\ Santa Maria, Brasil.
}

Recebido em: 20/11/2019 - Aprovado em: 15/12/2019 - Publicado em: 30/12/2019 DOI: 10.18677/Agrarian_Academy_2019b2

\begin{abstract}
RESUMO
A vegetação secundária em Floresta Estacional Decidual compreende maior formação florestal, quando comparado com as comunidades arbóreas sem intervenção antrópica. Fato este que justifica os estudos em áreas alteradas, para compreender como essas formações estão organizadas em espécies e de acordo com as condições do ambiente. Nesse sentido, o presente estudo objetivou analisar as variáveis ambientais que influenciam na composição da comunidade arbórea em uma área de encosta de Floresta Estacional Decidual. Para isso foi amostrada a vegetação em 50 parcelas de dimensões $10 \mathrm{~m} \times 20 \mathrm{~m}$, totalizando 1 ha de floresta. As variáveis ambientais utilizadas para análise foram: propriedades químicas e físicas do solo, topografia, cobertura de dossel e pedregosidade. Pelo programa $\mathrm{R}$ realizou-se uma PCA e NMDS. As variáveis de relevo, cobertura de dossel e o teor de fósforo no solo foram as mais significativas. As características morfológicas externas, como declividade e cobertura de dossel, influenciaram mais na formação da comunidade do que as características do solo.
\end{abstract}

PALAVRAS-CHAVE: Composição florística, Trecho florestal, Variáveis ambientais

\section{ARBOREAL COMPONENT REGARDING ENVIRONMENTAL HETEROGENEITY IN THE SOUTHERN PLATEAU, RS}

\begin{abstract}
ABSRACT
Secondary vegetation in Deciduous Seasonal Forest comprises greater forest formation when compared to tree communities without anthropic intervention. This fact justifies studies in altered areas to understand how these formations are organized into species and according to environmental conditions. In this sense, the present study aimed to analyze the environmental variables that influence the composition of the tree community in a slope area of Deciduous Seasonal Forest. For This The vegetation was sampled in 50 plots of $10 \mathrm{~m} \times 20 \mathrm{~m}$ dimensions, totaling
\end{abstract}


1 ha of forest. The environmental variables used for analysis are: chemical and physical properties of the soil, topography, canopy opening and percentage of stoniness. Through the R program a PCA and NMDS were performed. The variables of relief, canopy opening and soil phosphorus concentration were the most significant. External morphological characteristics, such as canopy slope and canopy opening, had a greater influence on community dynamics than soil characteristics.

KEYWORDS: Floristic composition, Forest trech, Environmental variables

\section{INTRODUÇÃO}

A Floresta Estacional Decidual apresenta alto índice de fragmentação, principalmente pelo avanço da agricultura (SCIPIONI et al., 2011). Como consequência, a perda da composição florística contínua, deixou a mesma com histórico de pequenos aglomerados em condições de remanescentes ou trechos de floresta secundária (LONGHI et al.,1999). As ações antropogênicas como desmatamento e incêndios florestais são, causadoras de danos irreparáveis como a perda da biodiversidade e das alterações climáticas.

A maioria das áreas de vegetação secundária são provenientes do abandono após o esgotamento dos recursos naturais do solo pela produção agrícola, associada a um solo lixiviado e empobrecido (KILKA; LONGHI, 2011). Assim, pela sucessão florestal, a vegetação se repõe ao ambiente pelos estágios iniciais, intermediário e avançado de composição.

Ainda, a estrutura de uma comunidade é o reflexo das interações entre as espécies com os gradientes ambientais existentes (HIGUCHI et al., 2013, 2014). Essas relações são as que norteiam a mudança sucessional, possibilitando o ingresso de novas espécies como o estabelecimento de outras, na organização da cobertura vegetal no espaço e no tempo (SCHAEFER et al., 2015). Além do mais, como observado por Ghiel et al. (2007), um gradiente ambiental pode estar relacionado com a distribuição espacial das espécies dentro da floresta.

Nesse sentido, este estudo objetivou analisar as variáveis ambientais que influenciam na composição da comunidade arbórea em uma área de encosta de Floresta Estacional Decidual, no município de Dona Francisca, RS.

\section{MATERIAL E MÉTODOS}

\section{Área de estudo}

O presente estudo foi realizado entre 2016 e 2019, em um trecho de Floresta Estacional Decidual, no município de Dona Francisca, nas coordenadas 29³'30.86"S e 5321'45.12"O, Rio Grande do Sul. A vegetação é a Floresta Estacional Decidual, sob clima do tipo Cfa, com chuvas bem distribuídas durante o ano e duas estações definidas (ALVARES et al., 2013).

De acordo com o histórico de uso relatado pelos proprietários, a vegetação primária foi suprimida para posterior conversão da área em cultivo de tabaco. Devido à dificuldade de acesso, a gleba foi abandonada há, aproximadamente, 50 anos, o que permitiu o estabelecimento de uma vegetação secundária (MISSIO, 2019).

A heterogeneidade ambiental está representada por nascentes, curso d'água, topografia com relevo ondulado a forte ondulado. Os solos da região são classificados em Argissolos e Cambissolos associados à Neossolos litólico (PEDRON; DALMOLIN, 2011). 


\section{Amostragem da vegetação}

Para o levantamento florístico - fitossociológico foram alocadas 50 parcelas

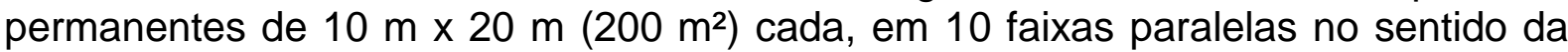
base ao topo da encosta, de modo sistemático. As parcelas foram estabelecidas com distância de $10 \mathrm{~m}$ entre si e $40 \mathrm{~m}$ entre faixas, totalizando 1 ha de amostragem (Figura 1).

Foram amostrados todos os indivíduos adultos que apresentassem limite mínimo para inclusão CAP $\geq 15,7 \mathrm{~cm}$ (circunferência a altura do peito, medida a $1,30 \mathrm{~m}$ do solo). Os indivíduos bifurcados abaixo de $1,30 \mathrm{~m}$, quando a raiz quadrada da soma dos quadrados apresentasse circunferência $\geq 15,7 \mathrm{~cm}$, permaneceram na amostragem.

As espécies foram identificadas in loco e quando não possível foi coletado material botânico, fértil ou estéril, e encaminhado à consulta de especialistas ou comparado à literatura de Sobral et al. (2013), no Herbário do Departamento de Ciências Florestais (HDCF), na Universidade Federal de Santa Maria. As espécies foram identificadas em nível de família, sendo classificadas de acordo com a APG IV (ANGIOSPERM PHYLOGENY GROUP, 2016) e o nome científico atualizado conforme a Lista de Espécies da Flora do Brasil (JBRJ, 2019).

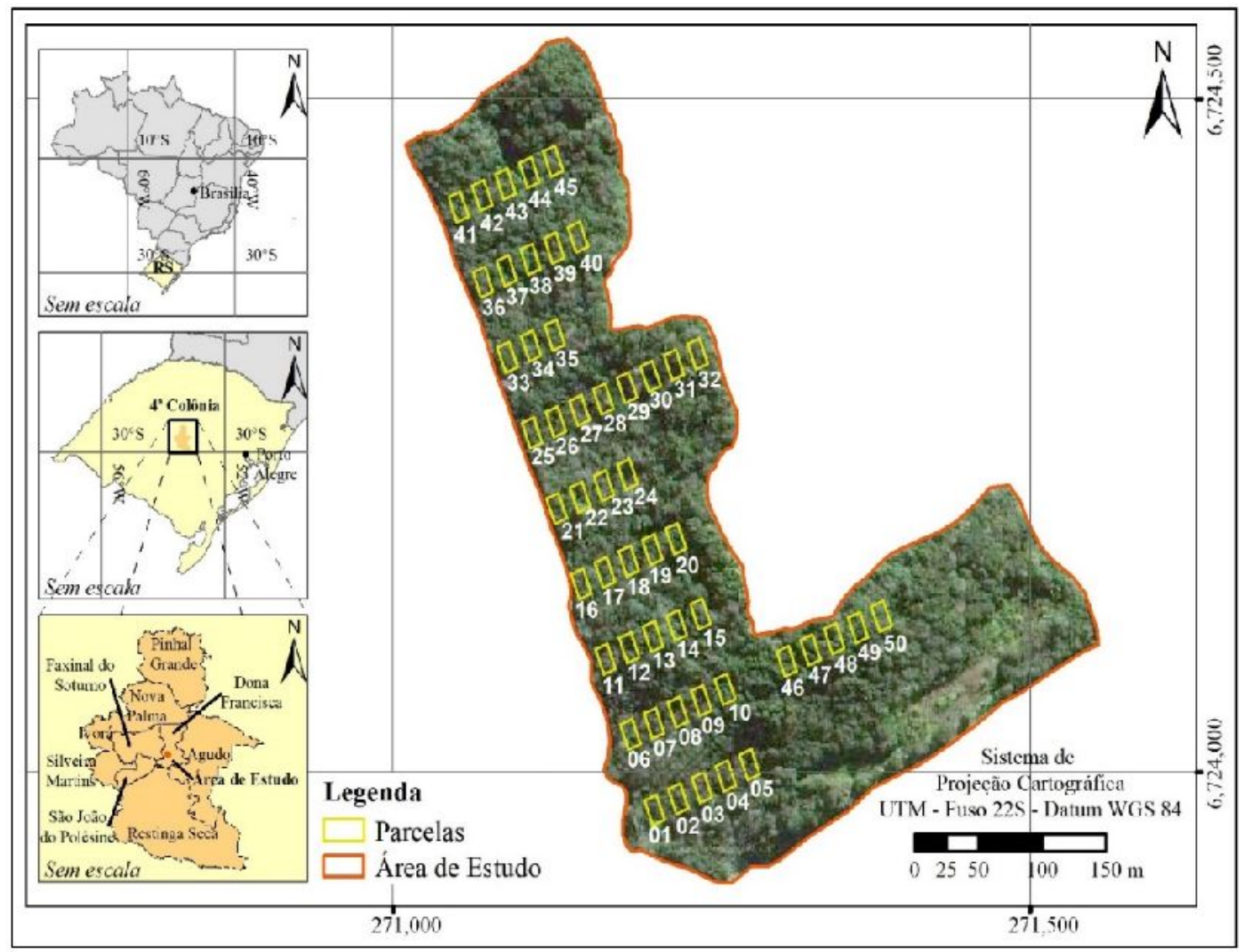

FIGURA 1. Localização da área de estudo e disposição das 50 parcelas em 10 faixas paralelas no trecho de Floresta Estacional Decidual, RS, Brasil, 2019. Fonte: Autores.

\section{Variáveis ambientais}

Amostras de solo foram coletadas na camada de $0-20 \mathrm{~cm}$. O solo foi seco ao ar, moído, passado em peneira com malha de $2 \mathrm{~mm}$ e preparado para análise. 
Determinou-se os valores $\mathrm{P}$ disponível (extraído por $\mathrm{Mehlich}^{-1}$ ), $\mathrm{K}$ disponível (extraído por Mehlich ${ }^{-1}$ ), Ca, Mg e Al trocáveis (ambos extraídos por (Tedesco et al., 1995). Calculou-se a acidez potencial $(\mathrm{H}+\mathrm{Al})$, CTC efetiva $\left(\mathrm{CTC}_{\mathrm{ef}}\right)$, CTC a pH7,0 $\left(\mathrm{CTC}_{\mathrm{pH}}\right)$, saturação por bases $(\mathrm{V} \%)$ e saturação por alumínio $(\mathrm{m} \%)$ (CQFS-RS/SC, 2016). Determinou-se os valores de areia, silte e argila (EMBRAPA, 2011).

As variáveis topográficas cota média $(\mathrm{m})$, desnível máximo $(\mathrm{m})$ e declividade média (\%), foram obtidas em cada parcela, com auxílio do Global Positioning System (GPSMAP 76CSx) e clinômetro de Suunto, utilizando a metodologia adaptada de Oliveira-Filho et al. (1994).

A pedregosidade foi observada visualmente e classificada em quatro classes, as quais foram atribuídas notas de 1 a 4 , de acordo com a quantidade de calhaus ou matacões: classe 1 - a superfície do terreno não apresenta calhaus e matacões; classe 2 - superfície do terreno ligeiramente pedregosa; classe 3 - calhaus e matacões distanciados 1,5 a $10 \mathrm{~m}$ na superfície e classe 4 - superfície do terreno pedregosa (adaptada de SANTOS et al., 2013).

A cobertura de dossel, uma medida indireta da quantidade de luz no interior da floresta, foi medida com densiômetro esférico côncavo modelo A (LEMMON, 1957), por meio de quatro leituras no sentido norte, sul, leste e oeste ao centro de cada parcela.

\section{Análise dos dados}

A média e o desvio padrão de cada variável ambiental quantitativa foram calculadas. Após, as variáveis ambientais foram analisadas por ordenação indireta, pela Análise de Componentes Principais (PCA), visando simplificar e melhor interpretar a heterogeneidade ambiental. Posteriormente, por meio da NMDS (Nonmetric multidimensional scalling) onde verificou-se a relação da composição florística, utilizando uma matriz de espécies com mais de cinco indivíduos e outra matriz com variáveis ambientais significativas $(p \leq 0,05)$, sendo excluídas as variáveis ambientais redundantes e de baixa significância. A interpretação da ordenação foi considerada pelo valor de stress. Todas as análises foram calculadas no programa $R$ (R DEVELOPMENT CORE TEAM, 2019).

\section{RESULTADOS E DISCUSSÃO}

Foram amostradas 65 espécies arbóreas e arbustivas (59 nativas, 7 exóticas e uma pteridófita), distribuídas em 31 famílias botânicas, com 2.045 indivíduos ha-1, que totalizaram $33,35 \mathrm{~m}^{2}$ ha-1 em área basal (MISSIO et al., no prelo). As famílias de maior riqueza em espécies nativas, máximo 11 espécies e mínimo 3, foram Fabaceae, Lauraceae, Myrtaceae, Euphorbiaceae, Meliaceae, Moraceae, Salicaceae e Sapindaceae (quadro 1). Dentre as espécies mais abundantes e de maior valor de importância, Casearia sylvestris, Nectandra lanceolata, Cupania vernalis e Guarea macrophylla representaram $57 \%$ da comunidade arbórea com 1.163 indivíduos arbóreos de DAP $\geq 5 \mathrm{~cm}$ (diâmetro a altura do peito maior ou igual a $5 \mathrm{~cm})$. 
QUADRO 1. Lista das famílias de maior riqueza amostradas em um trecho de encosta de Floresta Estacional Decidual, RS, Brasil, 2019.

\begin{tabular}{ll}
\hline FAMÍLIA/ESPÉCIE & FAMíLIA/ESPÉCIE \\
\hline EUPHORBIACEAE & Guarea macrophylla Vhale \\
Actinostemon concolor (Spreng.) Müll.Arg. & Melia azedarach L. \\
Alchornea triplinervia (Spreng.) Müll.Arg. & MORACEAE \\
Gymnanthes klotzschiana Müll.Arg. & Ficus sp. \\
FABACEAE & Ficus luschnathiana (Miq.) Miq. \\
Albizia niopoides (Spruce ex Benth) Burkart & Morus nigra L. \\
Apuleia leiocarpa (Vogel) J.F.Macbr. & Sorocea bonplandii (Baill.) \\
Bauhinia forficata Link & W.C.Burger et.al. \\
Dalbergia frutescens (Vell.) Britton & MYRTACEAE \\
Enterolobium contortisiliquum (Vell.) Morong. & Campomanesia guazumifolia \\
Erythrina falcata Benth. & (Cambess.) O. Berg. \\
Inga marginata Willd. & Campomanesia xanthocarpa \\
Lonchocarpus cf. nitidus (Vogel) Benth. & (Mart.) O.Berg. \\
Machaerium paraguariense Hassl. & Eugenia involucrata Dc. \\
Myrocarpus frondosus Allemão & Psidium guajava L. \\
Parapiptadenia rigida (Benth.) Brenan & SALICACEAE \\
LAURACEAE & Banara tomentosa Clos \\
Aiouea saligna Meisn. & Casearia decandra Jacq. \\
Nectandra lanceolata Ness & Casearia sylvestris Sw. \\
Nectandra megapotamica (Spreng.) Mez & SAPINDACEAE \\
Ocotea puberula (Rich.) Nees & Allophylus edulis (A.St-Hil.et.al.) \\
MELIACEAE & Hieron. ex Niederl. \\
Cabralea canjerana (Vell.) Mart. & Cupania vernalis Cambess. \\
Cedrela fissils Vell. & Matayba elaeagnoides Radlk. \\
\hline
\end{tabular}

Pela análise granulométrica, o solo classifica-se como franco-arenoso (EMBRAPA, 2013). Os baixos índices relativos ao complexo de acidez do solo, $\mathrm{pH}$ e o caráter eutrófico ( $\mathrm{V} \%>50 \%)$, resultam do histórico revolvimento da cobertura do solo, uso da queimada, retirada da serapilheira e correção por calagem no período em que a área esteve com cultivo de tabaco (Tabela 1).

Já as características externas relacionadas à topografia do terreno, cuja declividade média foi de $24,77 \%$, caracterizou-se o mesmo como ondulado a forte ondulado, de acordo com IBGE (2015). A cobertura de dossel indicou um índice de incidência luminosa na floresta, respectivamente de $31,3 \%$. Quanto à pedregosidade $60 \%$ da área ficou inserida na classe 2, de acordo com a classificação adaptada de Santos et al. (2013), o que condiz com a geomorfologia regional.

TABELA 1. Valores médios das variáveis ambientais quantitativas analisadas em um trecho de encosta de Floresta Estacional Decidual, RS, Brasil, 2019.

\begin{tabular}{lcc}
\hline Variáveis ambientais & Média & Desvio Padrão \\
\hline 1- Areia (\%) & 50,08 & 13,49 \\
2- Silte (\%) & 33,18 & 12,1 \\
3- Argila (\%) & 16,36 & 2,08
\end{tabular}

AGRARIAN ACADEMY, Centro Científico Conhecer - Goiânia, v.6, n.12; p. 19 


$\begin{array}{lcc}\text { 4- } \mathrm{pH} & 5,59 & 0,45 \\ \text { 5- } \mathrm{P}\left(\mathrm{mgdm}^{-3}\right) & 7,54 & 8,7 \\ \text { 6- } \mathrm{K}\left(\mathrm{mgdm}^{-3}\right) & 0,47 & 0,18 \\ \text { 7- } \mathrm{MOS}(\%) & 2,94 & 1,22 \\ \text { 8- } \mathrm{Al}\left(\mathrm{cmol}_{\mathrm{c}} \mathrm{dm}^{-3}\right) & 0,12 & 0,24 \\ \text { 9- } \mathrm{Ca}\left(\mathrm{cmol}_{\mathrm{c}} \mathrm{dm}^{-3}\right) & 6,91 & 2,9 \\ \text { 10-Mg }\left(\mathrm{cmol}_{\mathrm{c}} \mathrm{dm}^{-3}\right) & 1,58 & 0,65 \\ \text { 11-H+Al }\left(\mathrm{cmol}_{\mathrm{c}} \mathrm{dm}^{-3}\right) & 3,03 & 0,66 \\ \text { 12-CTC ef }\left(\mathrm{cmol}_{\mathrm{c}} \mathrm{dm}^{-3}\right) & 9,11 & 3,48 \\ \text { 13-CTC } \mathrm{pH} 7\left(\mathrm{cmol}_{\mathrm{c}} \mathrm{dm}^{-3}\right) & 12,02 & 3,29 \\ \text { 14-V\% } & 71,65 & 13,73 \\ \text { 15-m\% } & 2,78 & 6,43 \\ \text { 16-Cotm (m) } & 153,67 & 19,65 \\ \text { 17-Desmáx (m) } & 8,82 & 7,23 \\ \text { 18-Declimed (\%) } & 24,77 & 9,41 \\ \text { 19-CD (\%) } & 68,7 & 7,92\end{array}$

Em que: 1 - \% de areia; 2 - \% silte;3 - \% argila; 4 - $\mathrm{pH}$ em $\mathrm{H}_{2} \mathrm{O} ; 5$ - fósforo disponível; 6 potássio disponivel, 7 - \% de matéria orgânica no solo; 8 - alumínio trocável; 9- cálcio trocável, 10 - magnésio trocável; 11 - acidez potencial; 12 - CTC efetiva; 13 - CTC a $\mathrm{pH}=7 ; 14$ - saturação por bases; 15 - saturação por alumínio; 16 - cota média; 17 desnível máximo; 18 - declividade média; 19 - cobertura de dossel.

Em relação a tabela 2, verificou-se a correlação das variáveis ambientais correspondente aos eixos da PCA. Pelos resultados, foi possível observar que o eixo 1 da PCA explicou a maior variância dos dados que o eixo 2, apresentando maior conjunto de variáveis ambientais redundantes. Em detrimento deste aspecto, as variáveis ambientais mais correlacionadas com o segundo eixo, foram, respectivamente, aquelas também representadas na ordenação NMDS. Assim, as principais características relacionadas às propriedades químicas do solo, como as do complexo sortivo, não tiveram uma relação significativa com as espécies florestais. Destaca-se que a qualidade química do solo nem sempre será o fator condicionante, para a composição das espécies, como observado por Callegaro et al. (2017), Felker et al. (2017) e Rovedder et al. (2014). Por outro lado, outros trabalhos (ROVEDDER et al., 2013; BRAGA et al., 2015; HIGUCHI et al., 2016) retrataram as características físico-química do solo, como matéria orgânica e hidromorfia, importantes para a composição florística.

TABELA 2. Correlação das variáveis ambientais em relação aos eixos 1 e 2 da PCA, RS, Brasil, 2019.

\begin{tabular}{|c|c|c|c|c|c|}
\hline \multirow[b]{2}{*}{ Variáveis } & \multicolumn{2}{|c|}{ PCA } & \multirow[b]{2}{*}{ Variáveis } & \multicolumn{2}{|c|}{ PCA } \\
\hline & Eixo 1 & Eixo 2 & & Eixo 1 & Eixo 2 \\
\hline Areia & 0,2177 & $-0,0484$ & H.Al & 0,1992 & 0,1279 \\
\hline Silte & 0,2071 & 0,0593 & CTC.ef & $-0,2833$ & 0,0628 \\
\hline Argila & $-0,218$ & $-0,0522$ & CTC.pH7 & $-0,2747$ & 0,1193 \\
\hline
\end{tabular}




\begin{tabular}{cccccc}
\hline ph & $-0,2655$ & 0,0344 & V & $-0,2749$ & $-0,0723$ \\
P & $-0,1092$ & 0,4028 & m. & 0,2638 & 0,0299 \\
K & $-0,2577$ & 0,0725 & Cotm & $-0,0033$ & $-0,6211$ \\
MOS & $-0,2471$ & 0,1995 & Desmáx & $-0,1439$ & 0,1171 \\
Al & 0,2428 & 0,0053 & Decm & $-0,1779$ & $-0,3152$ \\
Ca & $-0,2847$ & 0,0738 & CD & $-0,2092$ & $-0,4784$ \\
Mg & $-0,2615$ & 0,0738 & Pedr & $-0,0853$ & 0,077 \\
\hline
\end{tabular}

De acordo com a ordenação NMDS, o valor do estresse foi de 14,67 \%, o que permitiu uma representação boa do ajuste linear (Figura 2). Verificou-se as quatro variáveis ambientais significativas, tais como: teor de fósforo, declividade média, cobertura de dossel e cota média.

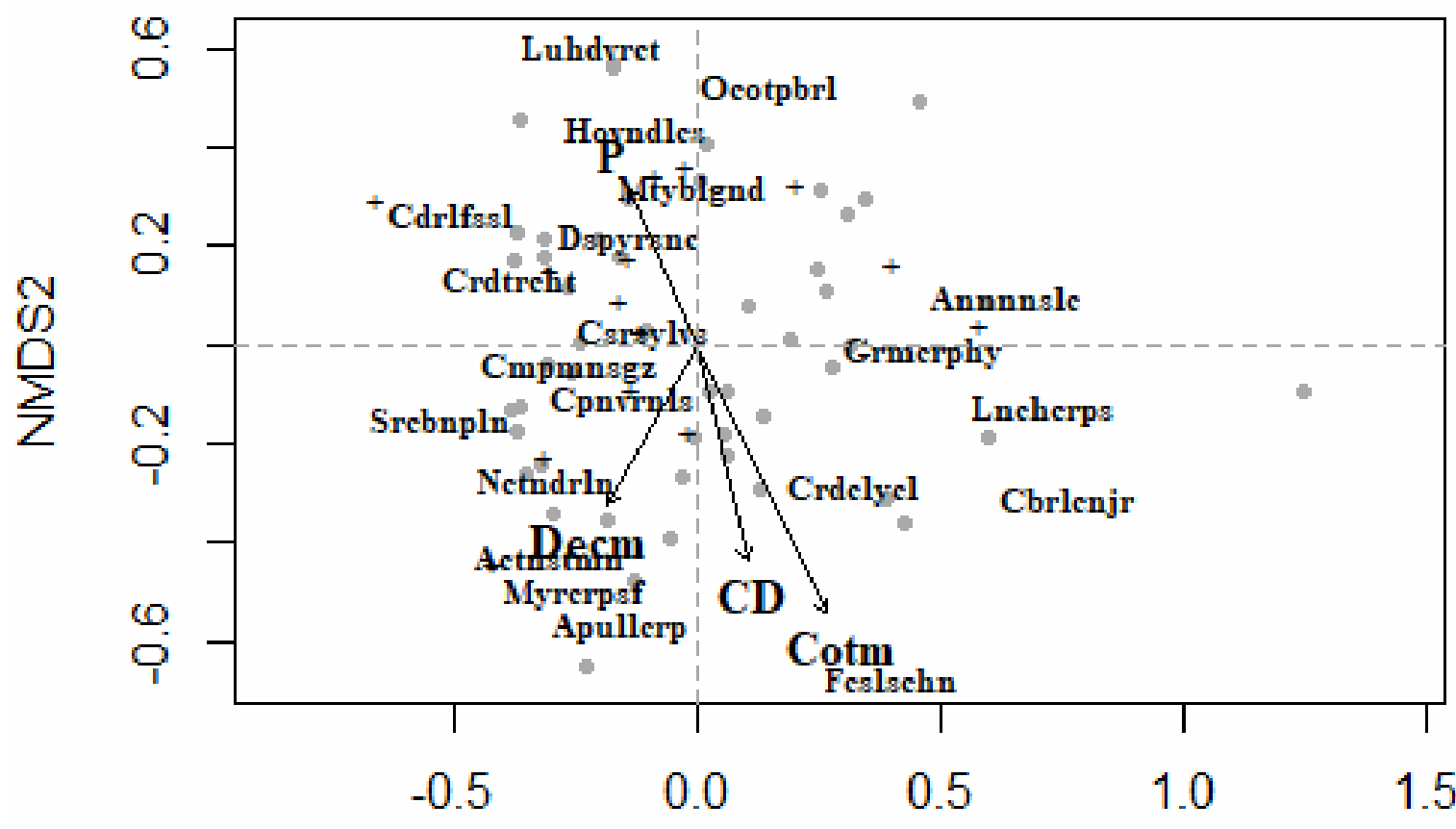

\section{NMDS1}

FIGURA 2. Ordenação NMDS das variáveis ambientais e vegetação em um trecho de encosta de Floresta Estacional Decidual, RS, Brasil, 2019. Em que: $P$ = fósforo; $\mathrm{CD}$ = cobertura de dossel; decm = declividade média; Cotm = cota média. Círculos fechados representam as parcelas. Símbolo "+" representa demais espécies.

Fonte: Autores.

No primeiro eixo da ordenação foi possível observar locais com maior teor de $\mathrm{P}$ no solo, estando o mesmo relacionado com a ocorrência principalmente das espécies Cordia trichotoma, Cedrela fissilis, Hovenia dulcis e Matayba elaeagnoides. No eixo inferior, luminosidade e condições de relevo estiveram ligadas principalmente com as espécies Actinostemon concolor, Myrocarpus frondosus, Apuleia leiocarpa e Ficus luschnathiana. Intermediárias à declividade, Cupania vernalis e Nectandra megapotamica. Já outras espécies, estão menos relacionadas AGRARIAN ACADEMY, Centro Científico Conhecer - Goiânia, v.6, n.12; p. 21 
com as variáveis ambientais significativas como a Annona neosalicifolia, Guarea macrophylla, Lonchocarpus nitidus e Cabralea canjerana, demonstrando que o ambiente não está sendo um fator limitante para a ocorrência das mesmas. Ainda, Casearia sylvestris não apresentou associação com as variáveis ambientais, estando localizada no centro da ordenação NMDS.

Higuchi et al. (2016) e Oliveira et al. (2015) também observaram a relação do fósforo na distribuição das espécies. O P é considerado essencial para as plantas e o teor do mesmo influencia na qualidade do sítio, em termos de biomassa via produção de serapilheira, bem como na ciclagem de nutrientes. No entanto, acredita-se que a alta concentração de fósforo representa um efeito residual do cultivo do tabaco, uma vez que é comum o uso de altas dosagens de fertilizantes. Dessa forma, a correlação significativa desse elemento com um grupo de espécies, pode demonstrar o caráter oportunista dessas, realizando consumo de luxo. Das espécies desse grupo, há evidências científicas de que Cordia trichotoma e Cedrela fissilis apresentam mecanismos de hiperacumuladoras para alguns elementos, como Zn e Cd (ACCIOLLY; SIQUEIRA, 2000). É possível que tal comportamento possa ocorrer em relação a outros elementos em abundância na solução do solo (OLIVEIRA; CARVALHO, 2008; FRANÇA et al., 2010; FRANÇA, 2016).

Considerando as características do solo em uma topossequência, a qual vai variar de acordo com a escala de mudanças do relevo, principalmente pela drenagem e profundidade do solo. Trabalhos, como de Rodrigues et. al. (2007), Cruz, Campos e Torezan (2018), apontaram a topografia como importante fator para as variações físico-químicas do solo em floresta nativa, bem como na densidade de espécies em relação a variação da cota altimétrica. Além disso, o uso agrícola pretérito pode ter favorecido perdas de solo no horizonte superficial, expondo um maior percentual de pedregosidade, situação típica de uso intensivo do solo em encostas declivosas. Da mesma forma, Scipioni et al. (2011) e Souza et al. (2015) observaram que o gradiente topográfico influenciou as condições edáficas e a distribuição das espécies arbóreas em Floresta Estacional Decidual.

A cobertura de dossel relacionada com a declividade, característica típica de floresta de encosta, elucida a importância da luminosidade no interior da floresta, principalmente na dinâmica de áreas de preservação permanente. A maior exposição pela abertura de clareiras que ocorrem pela queda das árvores, como observado in loco, favorece a disponibilidade de luz para o ingresso das espécies dependente de luz, como Hovenia dulcis, Luehea divaricata, Matayba elaeagnoides e Ocotea puberula. Estudos de Higuchi et al. (2015), Ansolini et al. (2016) e Callegaro et al. (2017) descreveram a luminosidade como variável importante para determinar a relação entre condições ambientais e vegetação.

Desse modo, nos locais de maior exposição aos feixes de luminosidade, o surgimento das espécies exigente em luz é mais favorecido. Nessas áreas ocorre, primeiramente, o fechamento do dossel, sendo uma condição coerente para a regeneração das espécies do sub-bosque, tolerantes a sombra como Actinostemon concolor. Já, para Apuleia leiocarpa, a relação positiva com a declividade, reflete no seu potencial em habitar áreas de encostas, associação condizente por ser uma espécie secundária inicial (FERREIRA JUNIOR et al., 2007)

Souza et al. (2017), também verificaram, para a espécie Ficus luschnathiana, sua preferência por locais de cotas mais altas, isto é, neste estudo a mesma esteve nas parcelas alocadas nos platôs. Do mesmo modo, Scipioni et. al. (2011) descreveram 
para Cupania vernalis e Nectandra megapotamica, abundância relacionada as porções intermediárias do relevo.

Para a espécie Casearia sylvestris, a ampla distribuição na área, é evidenciada pelo seu caráter generalista (OLIVERIA-FILHO; RATTER, 2000), o qual favoreceu a distribuição, não relacionada a fatores edáficos e demais variáveis ambientais.

Assim, quando comparado a outros estudos da região é possível verificar que, naturalmente, há uma diferença na relação da composição florística e estrutura ambiental, considerando ainda o histórico de uso da área antes da vegetação secundária. Callegaro et al. (2017) salientaram que ao comparar remanescentes florestais distantes, há uma tendência de encontrar maiores diferenças, tanto pela composição das espécies como pela heterogeneidade ambiental, do que na comparação da estrutura da floresta contínua. Do mesmo modo Martins (2012), afirmou que a composição florística pode ser semelhante no mesmo fragmento, no entanto, a variação das condições ambientais estabelece a heterogeneidade de espécies.

\section{CONCLUSÃO}

$\mathrm{Na}$ respectiva floresta de encosta foi possível observar uma heterogeneidade ambiental relacionada com as condições de uso da área após o cultivo de tabaco, como também pela localização característica de áreas no rebordo do Planalto Meridional. As espécies arbóreas estiveram relacionadas principalmente com as variáveis fósforo, luminosidade e relevo. No entanto, pelas duas ordenações, PCA e NMDS, ficou evidente que o componente arbóreo está sendo representado pelas espécies de exigências nutricionais menos seletivas.

A maioria das espécies florestais não foram exigentes na qualidade química do solo, a não ser pelo grupo de espécies relacionadas como possíveis acumuladoras do fósforo. Por outro lado, as características morfológicas externas relacionadas ao relevo forte ondulado, declividade e cobertura de dossel, para a composição florestal, apresentaram importância para a sucessão florestal.

\section{REFERÊNCIAS}

ACCIOLY, A. M. A.; SIQUEIRA, J. O. Contaminação química e biorremediação do solo. In: Tópicos em Ciência do Solo. Sociedade Brasileira de Ciência do Solo, Viçosa (MG), v.1, 2000.

ALVARES, C. A.; STAPE, J. L.; SENTELHAS, P. C.; de MORAES GONÇALVES, J. L.; SPAROVECK, GERD. Köppen's climate classification map for Brazil. Meteorologische Zeitschrift, Stuttgart, v. 22, n. 6, p.711-728, 2013. Disponível em: DOI: 10.1127 / 0941-2948 / 2013/0507

ANSOLINI, R. D. et al. Heterogeneidade ambiental e variação florístico-estrutural em um fragmento de Floresta com araucária na Coxilha Rica- SC. Ciência Florestal, Santa Maria, v.26, n.4, p.1201-1210, 2016. Disponível em: http://dx.doi.org/10.5902/1980509825111

APG IV. Angiosperm Phylogeny IV. Na update of the Angiosperm phylogeny Grop classification for the orders and families of flowering plants. Botanical Journal of the 
Linnean Society, London, v. 181, p. 1-20, 2016. Disponível em: https://doi.org/10.1111/boj.12385

BRAGA, A. J. T.; BORGES, E. de LIMA; MARTINS, S. V. Influência dos fatores edáficos na variação florística de Floresta Estacional semidecidual, em viçosa, MG. Árvore, Viçosa, v. 39, n. 4, p. 623-633, 2015. Disponível em: http://dx.doi.org/10.1590/0100-67622015000400004.

CALLEGARO, R. M. et al. Fitossociologia e fatores ecológicos condicionantes da vegetação em uma floresta estacional na região central do Rio Grande do Sul, Brasil. Revista Iheringa, Série Botânica, Porto Alegre, v. 72, n. 1, p. 33-43, 2017. Disponível em: https://isb.emnuvens.com.br/iheringia/article/view/618

Comissão de Química e Fertilidade do Solo - RS/SC. Manual de calagem e adubação para os Estados do Rio Grande do Sul e de Santa Catarina.

Sociedade Brasileira de Ciência do Solo. 2016. 376p.

CRUZ, M.P.; CAMPOS, J. B.; TOREZAN, J.M.D. Influência da topografia e da abertura do dossel na estrutura do componente herbáceo-arbustivo em dois fragmentos florestais na planície de inundação do Alto rio Paraná. Ciência. Florestal, Santa Maria, vol.28, n.1 2018. http://dx.doi.org/10.5902/1980509831652.

EMBRAPA- Empresa Brasileira de Pesquisa Agropecuária. CNPS- Centro Nacional de Pesquisa de Solos. Manual de métodos de análise de solos. 2. ed. Rio de Janeiro, 2011.

EMBRAPA- Empresa Brasileira de Pesquisa Agropecuária. CNPS- Centro Nacional de Pesquisa de Solos. Sistema brasileiro de classificação de solos. 3. ed. Rio de Janeiro, 2013. 376p.

FELKER, R.M. et al. Distribuição de Escallonia bífida Link \& Otto em relação às variáveis ambientais, em fragmentos florestais em vias de restauração no RS. Nativa, Sinópolis, V.5, n.2, p. 133-137, 2017.

FRANÇA, E.J.; FERNANDES, E.A.; BACCHI, M.A. Native plant bioaccumulation strategies: a baseline study for biomonitoring the Atlantic Forest. Journal Environment and Health, V. 4, p.181-200, 2010.

http://www.lerf.eco.br/img/publicacoes/Native\%20plant\%20bioaccumulation\%20strat egies\%20a\%20baseline\%20study\%20for\%20biomonitoring\%20the\%20Atlantic\%20F orest.pdf

FRANÇA, E.J.; de NADAI FERNANDES, E. A.; MIRANDA, M. V. F. E. S.; SANTOS, T. O.; CANTINHA, R. S. Cesium accumulation in natve trees from the Brazilian Cerrado. Journal of Radionalytical and Nuclear Chemistry, v. 310, p. 1123-1129, 2016. 
GIEHL, E. L. H; BUDKE, J. C.; ATHAYDE, E. A. Distribuição espacial de espécies arbóreas em uma floresta estacional em Santa Maria, Sul do Brasil. Pesquisas Botânicas, São Leopoldo, n. 58, p. 215-226, 2007.

http://www.anchietano.unisinos.br/publicacoes/botanica/botanica58/artigo07.pdf

HIGUCHI, P. et al. Florística e estrutura do componente arbóreo e análise ambiental de um fragmento de Floresta Ombrófila Mista Alto-Montana no município de Painel, SC. Ciência Florestal, Santa Maria, v. 23, n. 1, p. 153-164, 2013. Disponível em: http://dx.doi.org/10.5902/198050988449.

HIGUCHI, P. et al. Participação espacial de espécies arbóreas em função da drenagem da drenagem do solo em um fragmento de Floresta com araucária no Sul Brasil. Ciência Florestal, Santa Maria, v. 24, n. 2, p. 421-429, 2014. Disponível em: http://dx.doi.org/10.5902/1980509814580.

HIGUCHI, P. et al. Fatores determinantes da regeneração natural em um fragmento de floresta com araucária no planalto catarinense. Scientia Forestalis, Piracicaba,v. 43, n. 106, p. 251-259, 2015.

https://www.ipef.br/publicacoes/scientia/leitura.asp?Article=01\&Number=106\&p=s

HIGUCHI, P. et al. Florística e estrutura do componente arbóreo e relação com variáveis ambientais em um remanescente florestal em Campos Novos - SC. Ciência Florestal, Santa Maria, v. 26, n. 1, p. 35-46, 2016.

http://dx.doi.org/10.5902/1980509821089.

IBGE. Instituto Brasileiro de Geografia e Estatística. Manual técnico de pedologia. 3. ed. Rio de Janeiro: IBGE, 2015. 430 p.

JBRJ. Jardim Botânico do Rio de Janeiro. Lista de Espécies da flora doo Brasil. Disponível em < www.floradobrasil.jbrj.gov.br.> Acesso em: 25 agosto.2019.

KILKA, R. V.; LONGHI, S. J. A composição florística e a estrutura das florestas secundárias no Rebordo do Planalto Meridional. IN: CHUMACHER, M. V. et al. (Eds.). A Floresta Estacional Subtropical: caracterização e ecologia no Rebordo do Planalto Meridional. Santa Maria: Editora Pallotti, 2011. p. 53-83, 2011.

LEMMON, P. E. A new instrument for measuring fores tover story density. Journal of Forestry, Oxford, v. 55, n. 9, p. 667-668, 1957.

LONGHI, S. J. et al. Composição florística e estrutura da comunidade arbórea de um fragmento florestal no município de Santa Maria-Brasil. Ciência Florestal, Santa Maria, v. 9, n. 1, p. 115-133, 1999.

Disponível em: https://periodicos.ufsm.br/cienciaflorestal/article/view/371

MARTINS, S. M. Ecologia de florestas tropicais no Brasil. 2.ed. Viçosa, MG: Ed UFV, 2012. $371 \mathrm{p}$.

OLIVEIRA-FILHO, A. T.; VILELA, E. A.; CARVALHO, D. A.; GAVILANES, M. L. Differenciation of stream side and upland vegetation in na área of montane sem AGRARIAN ACADEMY, Centro Científico Conhecer - Goiânia, v.6, n.12; p. 25 2019 
ideciduous Forest in southeastern Brasil. Flora, Oxford, v. 189, p. 1-19, 1994. Disponível em: https://doi.org/10.1016/S0367-2530(17)30608-4

OLIVEIRA, P.C de; CARVALHO, C.J.de. Interações biofísicas em espécies arbóreas potencialmente acumuladoras de fósforo: diversidade de irradiância e de comportamento hídrico. Acta Botânica, RJ, v.38, n.3, p.445-452, 2008. Disponível em: https://www.embrapa.br/busca-de-publicacoes/-/publicacao/409731/interacoesbiofisicas-em-especies-arboreas-potencialmente-acumuladoras-de-fosforodiversidade-de-irradiancia-e-de-comportamento-hidrico.

OLIVEIRA, M. de L. A. A.; GRINGS, M.; RICHTER, F. S.; BACKES, A. R. Composição, estrutura e fatores edáficos condicionantes da distribuição das espécies do componente arbóreo em floresta ribeirinha do rio Ibirapuitã, Bioma Pampa. Revista Iheringia, Série Botânica, Porto Alegre, v. 70, n. 2, p. 245 - 263, 2015. Disponível em: https://isb.emnuvens.com.br/iheringia/article/view/389

PEDRON, F. de A.; DALMOLIN, R. S. D. Solos da região do Rebordo do Planalto Meridional no Rio Grande do Sul. In: SCHUMACHER, M. V. et al. A Floresta Estacional Subtropical: caracterização e ecologia no Rebordo do Planalto Meridional. Santa Maria: Editora Pallotti, 2011. p. 33-51.

OLIVERIA-FILHO, A.T.; RATTER, J.A. Padrões florísticos das matas ciliares da região do Cerrado e a evolução das paisagens do Brasil central durante o Quaternário tardio. In: RODRIGUES, R.R.; LEITÃO-FILHO, H. de F. (EDS.) Matas ciliares: conservação e recuperação. São Paulo: Editora da Universidade de São Paulo, p.73-89, 2000.

R DEVELOPMENT CORE TEAM. R: A language and environment for statistical computing. $R$ Foundation for Statistical Computing, 2019. Disponível em: $<$ (http://www.R-project.org)> Acesso em: 10/10/2019.

RODRIGUES, L. A.; CARVALHO, D. A. de.; OlIVEIRA FILHO, A. T.; CURI, N. Efeitos de solos e topografia sobre a distribuição de espécies arbóreas em um fragmento de floresta estacional semidecidual em Luminárias, MG. Árvore, Viçosa, v. 31, n. 1, p. 25-35, 2007. Disponível em: http://dx.doi.org/10.1590/S010067622007000100004 .

ROVEDDER, A.P.; SUZUKI, L. E. A. S.; DALMOLIN, R. S. D., REICHERT, J. M.; SCHENATO, R. B. Compreensão e aplicabilidade do conceito de solo florestal. Ciência Florestal. Santa Maria. V.23,n.3,p.517-528, 2013. Disponível em: http://dx.doi.org/10.5902/1980509810563

ROVEDDER, A. P.; ALMDEIDA, C. M.; ARAUJO, M. M.; TONETTO, T. S.; SCOTTI, M. S. V. Relação solo-vegetação em remanescente da floresta estacional decidual na Região Central do Rio Grande do Sul. Ciência Rural, Santa Maria, v. 44, n. 12, p. 2178-2185, 2014. Disponível em: http://dx.doi.org/10.1590/0103-8478cr20130698

SANTOS, R. S, dos. et al. Manual de descrição e coleta de solo no campo. 6. ed. Viçosa: Sociedade Brasileira de Ciência do Solo, 2013. 
SCHAEFER, C. E. G. R. et al. Relação solo-vegetação em formações vegetacionais brasileiras: metodologia e estudos de caso. In: EISENLOHR, P.V. et al. Fitossociologia no Brasil: métodos estudos de caso. Volume 2. Viçosa: Ed UFV, 2015. p. 322-343.

SCIPIONI, M. C.; LONGHI, S. J.; PEDRON, F. D.; ARAUJO, M. M. Análise dos padrões florísticos e estruturais da comunidade arbórea-arbustiva em gradientes de solo e relevo. In: SCHUMACHER, M. V. et al. (Eds.). A Floresta Estacional Subtropical: caracterização e ecologia no Rebordo do Planalto Meridional. Santa Maria: Editora Pallotti, p. 85-103, 2011.

SOBRAL, M.; et al. Flora arbórea e arborescente do Rio Grande do Sul, Brasil. 2.ed. São Carlos: RiMa, 2013, 357p.

SOUZA, K. et al. Estrutura e estratégias de dispersão do componente arbóreo de uma floresta subtropical ao longo de uma topossequência no Alto-Uruguai. Scientia Forestalis. Piracicaba. V. 43, n. 106, p. 321-332, jun. 2015. Disponível em: https://www.ipef.br/publicacoes/scientia/nr106/cap08.pdf

SOUZA, R.F. et al. Fitossociologia da vegetação arbórea do Parque Nacional do Iguaçu. Ciênc. Florest. Santa Maria, vol.27, n.3, 2017. Disponível em: https://periodicos.ufsm.br/cienciaflorestal/article/view/28635.

TEDESCO, M.J.; GIANELLO, C.; BISSANI, C.A.; BOHNEN, H. \& VOLKWEISS, S.J. Análise de solo, plantas e outros materiais. 2.ed. Porto Alegre, Universidade Federal do Rio Grande do Sul, 1995. 147p. (Boletim Técnico, 5). 